\title{
Co-cultures of multiple cell types mimic pulmonary cell communication in response to urban PM10
}

\author{
E. Alfaro-Moreno*\#, T.S. Nawrot*, B.M. Vanaudenaerde*, M.F. Hoylaerts", \\ J.A. Vanoirbeek*, B. Nemery* and P.H.M. Hoet*
}

ABSTRACT: The current authors evaluated whether a system of co-cultures of relevant cells (pneumocytes (A549), macrophages (THP-1), mast cells (HMC-1) and endothelial cells (EAHY926)) would mimic the responses to particles with a $50 \%$ cut-off aerodynamic diameter of $10 \mu \mathrm{m}$ (PM10) previously reported in vivo. The role of mast cells was considered of special interest.

Single cultures, bicultures (A549 + HMC-1 in a 10:1 ratio; THP-1 + HMC-1 in a 2:1 ratio) and tricultures (A549 + THP-1 + HMC-1 in a 10:2:1 ratio) were exposed to urban PM10 (24 h at 0, 10, 30 or $100 \mu \mathrm{g} \cdot \mathrm{cm}^{-2}$ ). Additionally, EAHY926 cells were introduced in inserts above the tricultures. The released cytokines were evaluated with a fluorescence-activated cell sorter array system.

THP-1 + HMC-1 bicultures and the tricultures released more granulocyte colony-stimulating

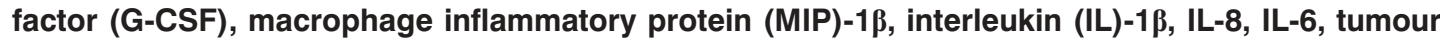
necrosis factor- $\alpha$ and MIP-1 $\alpha$ in response to PM10 than the sum of the single cultures. Tricultures

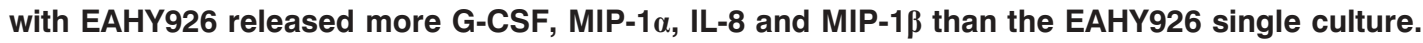

The bicultures, tricultures and tricultures with EAHY926 provide results that are consistent with the local and systemic effects previously described for particulate matter effects, i.e. inflammation, endothelial dysfunction and bone marrow cell mobilisation. Mast cells seem to play a significant role in the co-culture responses.

KEYWORDS: Co-culture, cytokine profile, particles with a $50 \%$ cut-off aerodynamic diameter of $10 \mu \mathrm{m}$, tricultures

tudies in vitro and in vivo have evaluated the pro-inflammatory effects of particulate matter (PM) [1, 2], but the role of communication between different pulmonary cell types is not well known. In this regard, IsHII and co-workers $[3,4]$ showed that the interaction between bronchial epithelial cells and macrophages led to an enhanced response to PM, and that this interaction was independent of cellular cross-linking.

Considering the complex architecture of airways and alveoli, the use of one and even two cell types is a far cry from reality. The interactions of epithelial cells and macrophages, i.e. the cells having direct contact with deposited particles, with other important cell types such as mast cells, dendritic cells, fibroblasts and endothelial cells, among others, ought to be important but they remain largely unknown. In the present study, the authors focused on the role of mast cells in the response to PM and the possible interaction of these cells with macrophages and epithelial cells, and the further interaction of co-cultures of these three cell types with endothelial cells.

Mast cells are an important component of the bronchial submucosa, the pleura and even the alveolar septa [5, 6]. Mast cells have not been studied much in relation to PM. However, histamine has been demonstrated to play an important role in the systemic effects of PM [7-9] and in its translocation [10], and considering that histamine is mainly secreted by mast cells, it seems that mast cells may be crucial to the understanding of the systemic effects of PM. Hence, the current authors evaluated the release of cytokines in response to PM, obtained in Mexico City (Mexico): by single cultures of mast cells, pneumocytes, macrophages and endothelial cells; by co-cultures of mast cells with pneumocytes or macrophages (bicultures); by co-cultures involving the three cell types (triculture); and by the interaction of these tricultures with

\section{AFFILIATIONS}

*Laboratory of Pneumology, Lung Toxicology Unit,

"Center for Molecular and Vascular Biology, Katholieke Universiteit Leuven, Leuven, Belgium.

\#Subdirección de Investigación Básica, Instituto Nacional de Cancerología, Mexico City, Mexico.

\section{CORRESPONDENCE}

E. Alfaro-Moreno

Katholieke Universiteit Leuven Laboratory of Pneumology

Lung Toxicology Unit

Herestraat 49

0\&N1 bus-706

B-3000 Leuven

Belgium

Fax: 3216347124

E-mail: ealfaro@salud.gob.mx

Received:

March 212008

Accepted after revision:

July 072008

SUPPORT STATEMENT

E. Alfaro-Moreno was supported by the European Respiratory Society

(Fellowship number 80), and currently by the Belgian Science Policy. T.S. Nawrot, B.M. Vanaudenaerde and J.A. Vanoirbeek are fellows of the Flemish Scientific Fund. The project was supported by a grant from the Interuniversitary Attraction Pole Program, Belgian State, Belgian Science Policy P6/35.

STATEMENT OF INTEREST None declared.

European Respiratory Journal Print ISSN 0903-1936

Online ISSN 1399-3003 
endothelial cells. The hypothesis was that the release of cytokines would differ qualitatively and quantitatively between pure cell cultures and mixed cell cultures.

\section{METHODS}

\section{Protocol design}

In order to evaluate the interactions and contributions of different cell types in the lung, a co-culture system was created with up to four different cell types. First, single cultures of lung epithelial cells (A549), macrophages (THP-1), mast cells (HMC-1) and endothelial cells (EAHY926) were studied. Secondly, co-cultures of two, three and four different cell types were prepared: bicultures of A549 with HMC-1 (10:1 ratio), and of THP-1 with HMC-1 (2:1 ratio); tricultures of A549, THP-1 and HMC-1 (10:2:1 ratio); and tricultures plus EAHY926 introduced in an insert after $12 \mathrm{~h}$ of exposure of the tricultures (fig. 1). The different cultures were exposed to particles with a 50\% cut-off aerodynamic diameter of $10 \mu \mathrm{m}$ (PM10) collected in Mexico City.

\section{PM sampling and preparation}

PM10 was collected, using a high-volume sampler (GMW Model 1200, VFC HVPM10; Sierra Andersen, Smyrna, GA, USA), in the industrial region of the Metropolitan Zone of Mexico City, in Xalostoc. Samples were collected during $24 \mathrm{~h}$ with an airflow rate of $1.13 \mathrm{~m}^{3} \cdot \mathrm{min}^{-1} \pm 10 \%$ on cellulose nitrate membranes with a nominal pore size of $3 \mu \mathrm{m}$ (11302-131; Sartorius, Göttingen, Germany). Sampling was performed three times a week, from November 2004 until April 2005.

The recovered particles were suspended in the required cell culture medium at a final concentration of $1 \mathrm{mg} \cdot \mathrm{mL}^{-1}$. The suspended particles were sonicated for $20 \mathrm{~min}$ to avoid the presence of particle clusters. Aliquots were taken to obtain the necessary final concentrations. The final exposure concentrations were expressed in $\mu \mathrm{g} \cdot \mathrm{cm}^{-2}$ in order to keep a consistent ratio of particulate mass/cell number/area [11].

\section{Cell culture}

The following human-derived cell lines were used: A549 (epithelial type II pneumocytes; American Type Culture Collection, Manassas, VA, USA) [12]; THP-1, a monocytederived cell line (American Type Culture Collection) differentiated into macrophage-like cells by overnight incubation with $1 \mathrm{ng} \cdot \mathrm{mL}^{-1}$ phorbol myristate acetate [13]; HMC-1 (mast cells; kindly provided by J.H. Butterfield, Mayo Clinic, Rochester, MN, USA) [14]; and EAHY926 (endothelial cells) [15]. The cell culture media used for the different cultures are described in table 1. All the experiments were performed in polystyrene 24-well plates (Costar Europe Ltd, Badhoevedorp, the Netherlands) seeded at a density of $1.6 \times 10^{5} \mathrm{cells} \cdot \mathrm{cm}^{-2}$. The
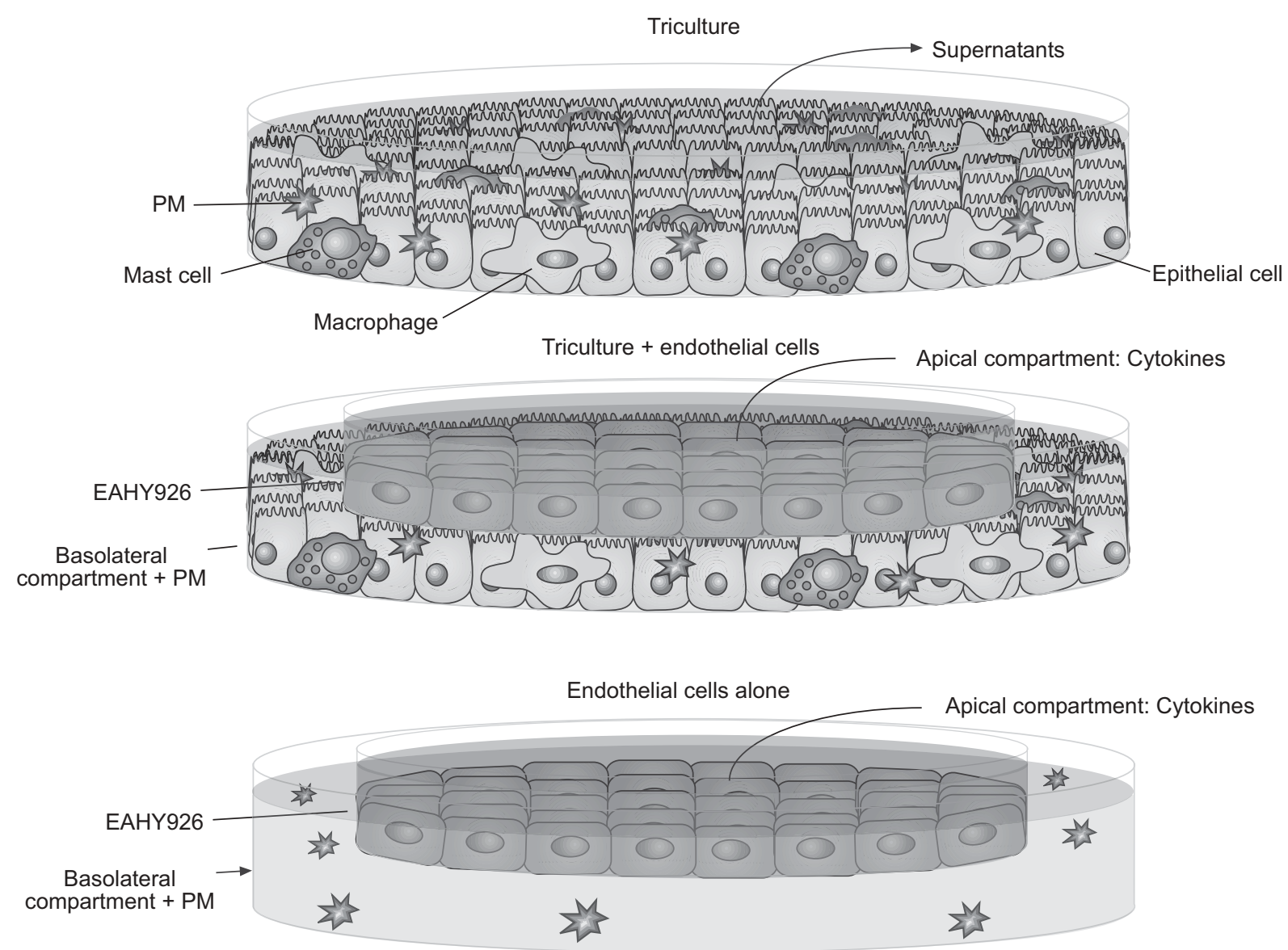

FIGURE 1. Schematic representation of the strategy of particulate matter (PM) exposure with tricultures, tricultures plus endothelial cells (EAHY926) and EAHY926 alone, and supernatant collection for further cytokine evaluations. 


\begin{tabular}{lcc} 
TABLE 1 & Media used for cellular culture & \\
Cell culture & Medium & Other \\
\hline Single cultures & & \\
A549 & DMEM & L-glutamine \\
THP-1 & RPMI & Phorbol myristate acet- \\
& ate \\
HMC-1 & Iscove's & $\alpha$-thioglycerol \\
EAHY926 & DMEM & HEPES \\
Co-cultures & & \\
A549 + HMC-1 & DMEM + Iscove's 10:1 \\
THP-1 + HMC-1 & RPMI + Iscove's 2:1 \\
Triculture & DMEM + RPMI + \\
Iscove's 10:2:1 & \\
Triculture + & Triculture medium + \\
EAHY926 & DMEM (HEPES) 3:1 \\
\hline
\end{tabular}

All the media were supplemented with foetal calf serum (10\%), penicillin $\left(100 \mathrm{U} \cdot \mathrm{mL}^{-1}\right)$, streptomycin $\left(100 \mu \mathrm{g} \cdot \mathrm{mL}^{-1}\right)$ and fungizone $\left(1.25 \mu \mathrm{g} \cdot \mathrm{mL}^{-1}\right)$. No foetal calf serum was added during exposure to particles with a $50 \%$ cut-off aerodynamic diameter of $10 \mu \mathrm{m}$. A549: epithelial type-II pneumocytes; THP-1: macrophage-like cells; HMC-1: mast cells; EAHY926: endothelial cells; DMEM: Dulbecco's modified Eagle medium; HEPES: hydroxyethyl piperazine ethane sulphonic acid.

EAHY926 cells were grown on polycarbonate Transwell inserts with a nominal pore size of $0.4 \mu \mathrm{m}$ (Costar Europe Ltd). After $24 \mathrm{~h}$, the medium was changed for medium without foetal calf serum (FCS).

To the current authors' knowledge, there is no report on the number of mast cells in the lung, so a ratio of 10:1 was chosen for the epithelial cell $\left(1.6 \times 10^{5}\right.$ cells $\left.\cdot \mathrm{cm}^{-2}\right)$ and mast cell $\left(0.16 \times 10^{5}\right.$ cells $\left.\cdot \mathrm{cm}^{-2}\right)$ biculture, and a $2: 1$ ratio for the macrophage $\left(1.07 \times 10^{5}\right.$ cells $\left.\cdot \mathrm{cm}^{-2}\right)$ and mast cell $\left(0.53 \times 10^{5}\right.$ cells $\left.\cdot \mathrm{cm}^{-2}\right)$ biculture.

Based on the evaluation of their in vivo distributions made by STONE et al. [16], a ratio of 5:1 was chosen when co-cultures of epithelial cells and macrophages were used. The tricultures of A549 + THP-1 + HMC-1 cells were seeded in a ratio of 10:2:1, i.e. $1.6 \times 10^{5}, 0.32 \times 10^{5}$ and $0.16 \times 10^{5} \mathrm{cells} \cdot \mathrm{cm}^{-2}$, respectively (fig. 1). The tricultures with endothelial cells consisted of adding an insert containing confluent EAHY926 cells, thus creating another compartment above the tricultures after $12 \mathrm{~h}$ of exposure to PM. The EAHY926 cells were never in direct contact with the PM (fig. 1).

All incubations with PM were performed with FCS-free medium. The cell culture medium was changed for FCS-free medium $6 \mathrm{~h}$ before exposure to PM. The cultures were exposed to $0,10,30$ or $100 \mu \mathrm{g} \cdot \mathrm{cm}^{-2}$ of PM10 and after $24 \mathrm{~h}$ the supernatants were recovered and stored at $-80^{\circ} \mathrm{C}$ for further analyses.

\section{Cytokine release}

\section{Qualitative analysis}

In preliminary experiments, supernatants from the single cultures, the tricultures and the tricultures with endothelial cells exposed to 0 or $100 \mu \mathrm{g} \cdot \mathrm{cm}^{-2}$ were evaluated to establish a cytokine secretion profile by a semiquantitative technique (Proteome Profiler, Human Cytokine Array Kit; R\&D Systems Inc., Minneapolis, MN, USA). The obtained autoradiographs were scanned and analysed using the ImageJ program (National Institutes of Health, Bethesda, MD, USA). The relative density of each dot was calculated in relation to the positive internal controls of the membranes and the results were expressed as fold changes above or below the unexposed cultures. Changes of $<0.5$ or $>1.5$ were considered relevant. Those cytokines presenting a relevant change were selected for further analysis and quantification.

\section{Quantitative analysis}

Based on the results of the Human Cytokine Array, tumour necrosis factor (TNF)- $\alpha$, interleukin (IL)-1 $\beta$, IL-6, IL-8, macrophage inflammatory protein (MIP)-1 $\alpha$, MIP-1 $\beta$, monocyte chemotactic protein (MCP)-1, granulocyte colony-stimulating factor (G-CSF), interferon (IFN)- $\gamma$ and RANTES were selected for quantitative analysis using a Cytometric Bead Array Flex (BD Biosciences, Erembodegem, Belgium), acquired with the FACSArray (BD Biosciences) in $50 \mu \mathrm{L}$ of the supernatants using the FCAP Array software (BD Biosciences).

\section{Statistical analysis}

Due to the variability of the cytokine release in the different cell culture conditions, the results are presented as percentages of the concentrations in the unexposed cultures. To evaluate the concentrations of cytokines in the co-cultures (and to put these results into perspective), the results from the co-cultures were also compared with the "expected" concentrations obtained by adding up the amounts secreted in the single cultures and adjusting for the number of cells. Differences across the three PM concentrations were investigated by ANCOVA. For testing the effect of PM on co-cultures, data from the single cultures, adjusted for cellular density, were used to calculate an expected additive effect for each concentration. A possible multiplicative effect at the different concentrations was studied by two-way ANOVA with interaction testing between the additive data and the observed data. Differences were considered significant when $\mathrm{p}<0.05$ (two-tailed).

\section{RESULTS}

\section{Qualitative analysis (cytokine array)}

Supernatants collected from single cultures evaluated by the Proteome Profiler Human Array kit (table 2; fig. 2) showed that A549 cells exposed to PM exhibited a large decrease in the levels of IL-8 (0.27-fold), growth-related oncogene (GRO)- $\alpha$ (0.25-fold) and IL-23 (0.3-fold), while no relevant increase was observed for any cytokine. In contrast, the THP-1 cells exposed to PM exhibited increases in MIP-1 $\beta$ (1.5-fold), RANTES (1.5-fold), soluble intercellular adhesion molecule (sICAM; 2-fold) and TNF- $\alpha$ (90-fold), and decreases in IL- 8 (0.23-fold) and MIP- $1 \alpha$ (0.5-fold). HMC- 1 cells presented an increase in the secretion of IL-1 $\beta$ (3.5-fold) and sICAM (2.7-fold) but decreases in the levels of I-309 (0.35-fold), IL-32 (0.11-fold) and MCP-1 (0.05-fold).

In the triculture, increases were observed for G-CSF (4.4-fold), sICAM (1.5-fold), IL-1 $\beta$ (2.6-fold), IL-6 (4.4-fold), MIP-1 $\alpha$ (8.4fold) and MIP-1 $\beta$ (13.4-fold), and a decrease in RANTES (0.32fold). The supernatants from the apical compartment of the endothelial cells exhibited increases in the levels of G-CSF 


\begin{tabular}{|c|c|c|c|c|c|}
\hline \multirow[t]{2}{*}{ Cytokine } & \multicolumn{5}{|c|}{ Cell culture } \\
\hline & A549 & THP-1 & HMC-1 & Triculture & $\begin{array}{c}\text { Triculture + } \\
\text { EAHY926 }\end{array}$ \\
\hline G-CSF & & & & 4.4 & 22.5 \\
\hline GRO- $\alpha$ & 0.25 & & & & 0.5 \\
\hline $1-309$ & & & 0.35 & & 0.07 \\
\hline SICAM & & 2 & 2.7 & 1.5 & \\
\hline IL-1 $\beta$ & & & 3.5 & 2.6 & \\
\hline IL-6 & & & & 4.4 & \\
\hline IL-8 & 0.27 & 0.23 & & & \\
\hline IL-23 & 0.3 & & & & \\
\hline IL-32 & & & 0.11 & & \\
\hline MCP-1 & & & 0.05 & & 0.04 \\
\hline MIP-1 $1 \alpha$ & & 0.5 & & 8.4 & 65 \\
\hline MIP-1 $1 \beta$ & & 1.5 & & 13.4 & \\
\hline RANTES & & 1.5 & & 0.32 & 0.1 \\
\hline TNF- $\alpha$ & & 90 & & & \\
\hline
\end{tabular}

Data are presented as fold changes after exposure to particles with a $50 \%$ cutoff aerodynamic diameter of $10 \mu \mathrm{m}\left(100 \mu \mathrm{g} \cdot \mathrm{cm}^{-2}\right)$ compared with unexposed cultures, as calculated from the semiquantitative array membranes (fig. 2). Cytokines with a variation $>50 \%$ in relation to the control were considered relevant and are expressed in this table. A549: epithelial type-II pneumocytes; THP-1: macrophage-like cells; HMC-1: mast cells; EAHY926: endothelial cells G-CSF: granulocyte colony-stimulating factor; GRO: growth-related oncogene; sICAM: soluble intercellular adhesion molecule; IL: interleukin; MCP: monocyte chemotactic protein; MIP: macrophage inflammatory protein; TNF: tumour necrosis factor

(22.5-fold) and MIP- $1 \alpha$ (65-fold), but decreases for GRO- $\alpha$ (0.5fold), I-309 (0.07-fold), MCP-1 (0.04-fold) and RANTES (0.1-fold).

\section{Quantitative analysis}

Single cultures

A549 cells exposed to PM10 (fig. 3a and b) did not show an increase in any evaluated cytokine, but showed significant concentration-related reductions in the secretion of IL-8, MCP-1 and RANTES (table 3).

THP-1 cells exposed to PM10 (fig. 3c and d) exhibited increases more than four-fold in the levels of TNF- $\alpha$ and IFN- $\gamma$ and decreases in the levels of MCP-1. IL-8 had a slight increase at a low concentration of PM10 $\left(10 \mu \mathrm{g} \cdot \mathrm{cm}^{-2}\right)$ and a decrease at high concentration $\left(100 \mu \mathrm{g} \cdot \mathrm{cm}^{-2}\right.$; table 3$)$.

For the HMC-1 cells exposed to PM10 (fig. $3 e$ and f), no increase was observed for any of the evaluated cytokines, and significant decreases were observed for IL-6, TNF- $\alpha$, MIP- $1 \alpha$ and MCP-1 (table 3).

\section{Bicultures}

In the bicultures of A549 + HMC-1 cells exposed to PM10, no significant increase was observed for any of the evaluated cytokines, but decreases up to $90 \%$ were observed for IL-1 $\beta$,
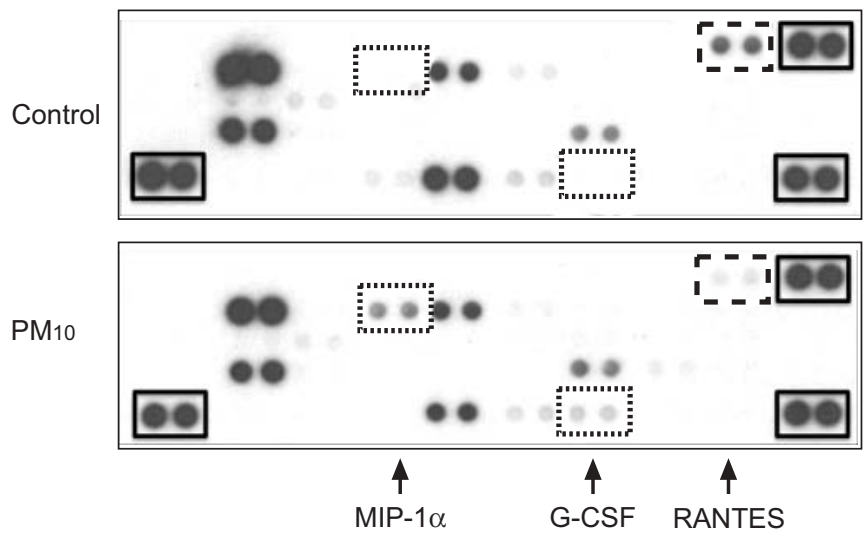

FIGURE 2. Protein array presenting the relative changes of the cytokine concentrations in medium of tricultures exposed for $24 \mathrm{~h}$ to 0 (control) or $100 \mu \mathrm{g} \cdot \mathrm{cm}^{-2}$ of particles with a $50 \%$ cut-off aerodynamic diameter of $10 \mu \mathrm{m}$ (PM10). The boxes show examples of proteins that are upregulated $(\cdots \cdots \cdot$ granulocyte colony-stimulating factor (G-CSF) and macrophage inflammatory protein (MIP)-1 $\alpha$ ) and downregulated (-- - -; RANTES), as well as internal positive controls (-). The relative density of each dot was calculated in relation to the internal positive controls and the change in the intensity of the signal was calculated as a ratio between exposed and unexposed cultures and expressed as percentage change. The change was considered relevant when $>50 \%$ (table 2).

IL-8 and MCP-1 (fig. 4a and b; table 3). The co-cultures of THP-1 + HMC-1 (macrophages and mast cells) induced the most significant changes (fig. $4 \mathrm{c}$ and $\mathrm{d}$; table 3). Large increases were observed for G-CSF ( $>10$-fold), MIP- $1 \alpha$, MIP$1 \beta$, IL-1 $\beta$ (up to eight-fold), IL-6 and TNF- $\alpha$ (up to 100-fold). In contrast, decreases were observed for the levels of RANTES and MCP-1. IL- 8 exhibited increases at 10 and $30 \mu \mathrm{g} \cdot \mathrm{cm}^{-2}$ PM10, but a return to basal levels at $100 \mu \mathrm{g} \cdot \mathrm{cm}^{-2}$.

\section{Tricultures}

In tricultures exposed to PM10, significant increases were observed for G-CSF (up to six-fold), IL-1 $\beta$, IL-6 (up to 7.5-fold), TNF- $\alpha$ (up to 20-fold) and MIP- $1 \alpha$. With increasing PM10 concentration, an increase followed by a decrease compared with basal levels was observed for MIP-1 $\beta$, IL-8 and MCP-1. A significant decrease was observed for RANTES (fig. 5a and b; table 3).

Tricultures with endothelial cells and endothelial cells alone

The supernatants from the endothelial cells co-cultured with the tricultures exposed to PM10 presented significant increases in IL-6 (up to 7.5-fold), MIP-1 $\beta$, IL-8 and MCP-1, but a decrease in RANTES (fig. $5 \mathrm{c}$ and $\mathrm{d}$; table 3 ). The endothelial cells exposed to only the medium with PM10 in the basolateral compartment exhibited increases in the levels of TNF- $\alpha$ (up to 12 -fold) and G-CSF, and no significant variations in all the other cytokine mediators (fig. 5e and f; table 3).

\section{Observed versus expected cytokine concentrations}

The results of the concentrations of TNF- $\alpha$, G-CSF and IL- 8 in THP-1 + HMC-1 bicultures, tricultures and tricultures with endothelial cells after exposure to PM10 are presented in 

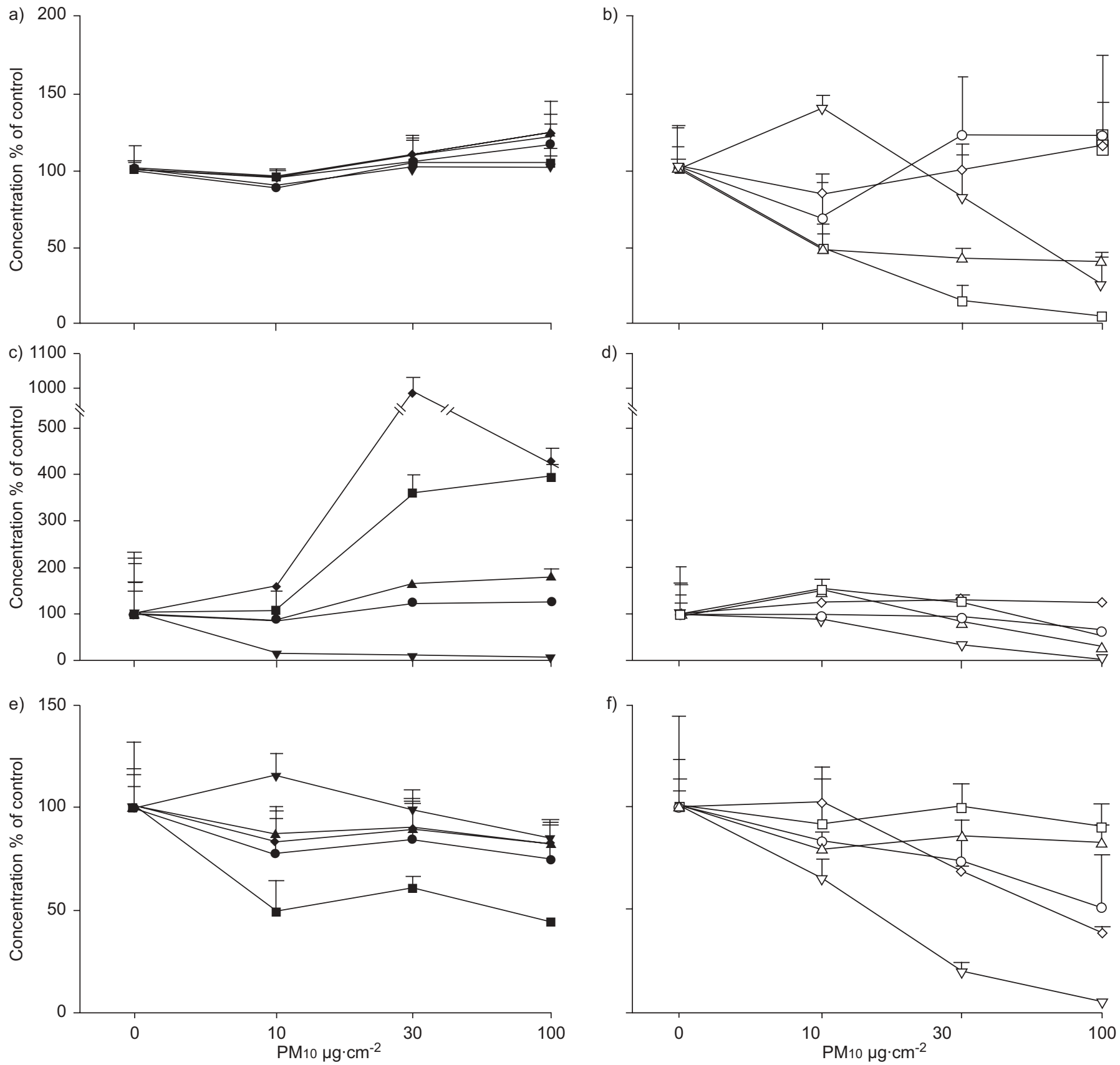

FIGURE 3. Cytokine secretion profile in cultures of a and b) A549 (epithelial type-ll pneumocytes), c and d) THP-1 (macrophage-like cells) or e and f) HMC-1 (mast cells) cells exposed for $24 \mathrm{~h}$ to $0,10,30$ or $100 \mu \mathrm{g} \cdot \mathrm{cm}^{-2}$ of particles with a 50\% cut-off aerodynamic diameter of $10 \mu \mathrm{m}$ (PM10). The cytokine levels are expressed as percentage of control $\left(0 \mu \mathrm{g} \cdot \mathrm{cm}^{-2} \mathrm{PM} 10\right)$. Data are presented as mean $\pm \mathrm{SD} ; \mathrm{n}=3$. $\mathbf{\boldsymbol { q }}$ : tumour necrosis factor- $\alpha ; \boldsymbol{\bullet}$ : interleukin (IL)-1 $\beta ; \mathbf{\Lambda}:$ granulocyte colony-stimulating factor; $\mathbf{\nabla}$ : IL-6; interferon- $\gamma ; \square:$ IL-8; $\bigcirc$ : macrophage inflammatory protein (MIP)-1 $\beta ; \triangle$ : RANTES; $\nabla:$ monocyte chemotactic protein-1; $\diamond:$ MIP-1 $\alpha$.

figure 6, compared with the expected concentrations based on the single cultures and corrected for the cell number.

\section{DISCUSSION}

To date, the use of conditioned medium and co-cultures of macrophages plus epithelial cells have been useful for the evaluation of PM-induced effects $[4,17,18]$ but, in the present study, two more players were added: mast cells and endothelial cells. The use of multiple cellular types, relevant for the local and systemic effects attributed to PM, shows that regulation of cytokine secretion in single cell cultures can be amplified/mitigated in co-cultures. The pattern of cytokine secretion after exposure to PM appears to correspond to the in vivo effects related to PM. The most important and novel observation in the present in vitro system is that the interaction between mast cells and macrophages leads to an amplified response to PM. These amplifications may mimic what really occurs in the lung, especially in lungs from allergic subjects. 


\section{TABLE 3 Overall p-values for percentage changes in cytokine concentrations}

Cell culture

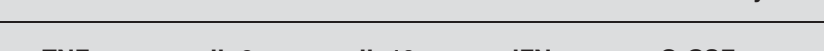

\begin{tabular}{|c|c|c|c|c|c|c|c|c|c|c|}
\hline A549 & & & & & & $<0.001^{\#}$ & $<0.001^{\circ}$ & & & $<0.001^{\#}$ \\
\hline THP-1 & $<0.001^{+}$ & & & $0.029^{+}$ & & $<0.055^{\circ}$ & $0.025^{\#}$ & & & $0.016^{\#}$ \\
\hline HMC-1 & $0.02^{\#}$ & $0.02^{\#}$ & & & & & $<0.001^{\#}$ & & $<0.001^{\#}$ & \\
\hline A549 + HMC-1 & & & $0.0371^{\#}$ & & & $<0.001^{\#}$ & $<0.001^{\#}$ & & & \\
\hline THP-1 + HMC-1 & $<0.001^{+}$ & $<0.001^{+}$ & $<0.001^{+}$ & & $<0.001^{+}$ & $<0.001^{\circ}$ & $<0.001^{\#}$ & $<0.001^{+}$ & $<0.001^{+}$ & $<0.001^{\#}$ \\
\hline Triculture & $<0.001^{+}$ & $0.016^{+}$ & $0.04^{+}$ & & $0.048^{+}$ & $0.005^{\circ}$ & $0.051^{\bullet}$ & $0.005^{\circ}$ & $0.019^{+}$ & $0.024^{\#}$ \\
\hline
\end{tabular}

TNF: tumour necrosis factor; IL: interleukin; IFN: interferon; G-CSF: granulocyte colony-stimulating factor; MCP: monocyte chemotactic protein; MIP: macrophage inflammatory protein; A549: epithelial type-II pneumocytes; THP-1: macrophage-like cells; HMC-1: mast cells; EAHY926: endothelial cells. ${ }^{*}$ : overall decrease of the cytokine; ${ }^{\top}$ : increases of the cytokine at low concentrations (10 or $30 \mu \mathrm{g} \cdot \mathrm{cm}^{-2}$ ) and decreases at high concentrations $\left(100 \mu \mathrm{g} \cdot \mathrm{cm}^{-2}\right)$ of particles with a $50 \%$ cut-off aerodynamic diameter of $10 \mu \mathrm{m} ;{ }^{+}$: overall increase of the cytokine.
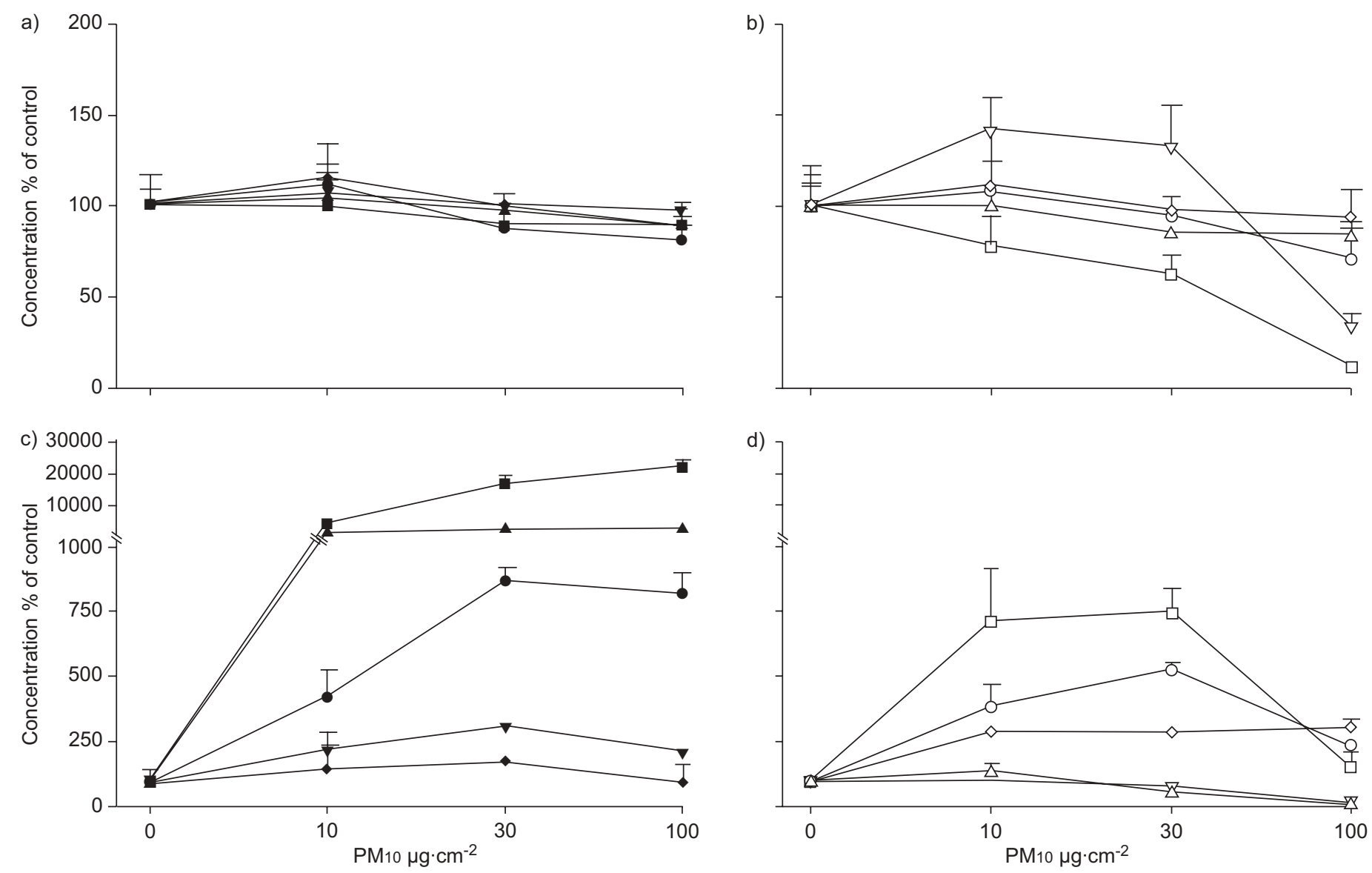

FIGURE 4. Cytokine secretion profile in bicultures. a and b) A549 (epithelial type-Il pneumocytes) + HMC-1 (mast cells), and c and d) THP-1 (macrophage-like cells) + HMC-1. Bicultures were exposed for $24 \mathrm{~h}$ to $0,10,30$ or $100 \mu \mathrm{g} \cdot \mathrm{cm}^{-2}$ of particles with a $50 \%$ cut-off aerodynamic diameter of $10 \mu \mathrm{m}$ (PM10). The cytokine levels are expressed as percentage of control $\left(0 \mu \mathrm{g} \cdot \mathrm{cm}^{-2} \mathrm{PM} 10\right)$. Data are presented as mean $\pm \mathrm{SD} ; \mathrm{n}=3$. $\mathbf{\square}$ : tumour necrosis factor- $\alpha ; \boldsymbol{\bullet}$ : interleukin (IL)-1 $\beta ; \mathbf{\Lambda}:$ granulocyte colony-stimulating factor; $\mathbf{\nabla}:$ IL-6; $\diamond$ : interferon- $\gamma ; \square$ : IL-8; $\bigcirc:$ macrophage inflammatory protein (MIP)-1 $\beta ; \triangle$ : RANTES; $\nabla$ : monocyte chemotactic protein-1; $\diamond:$ MIP-1 $\alpha$. 

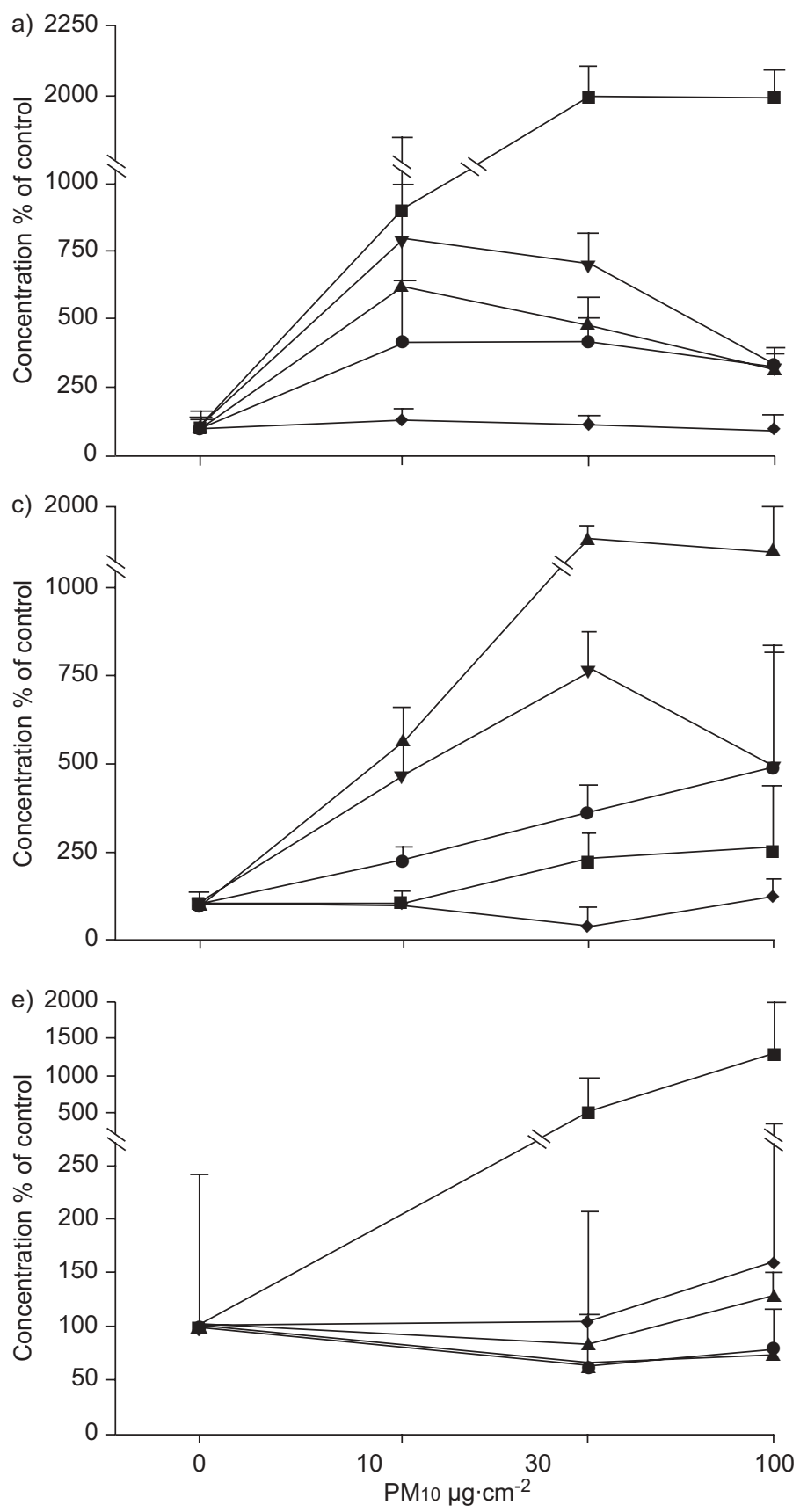

b)

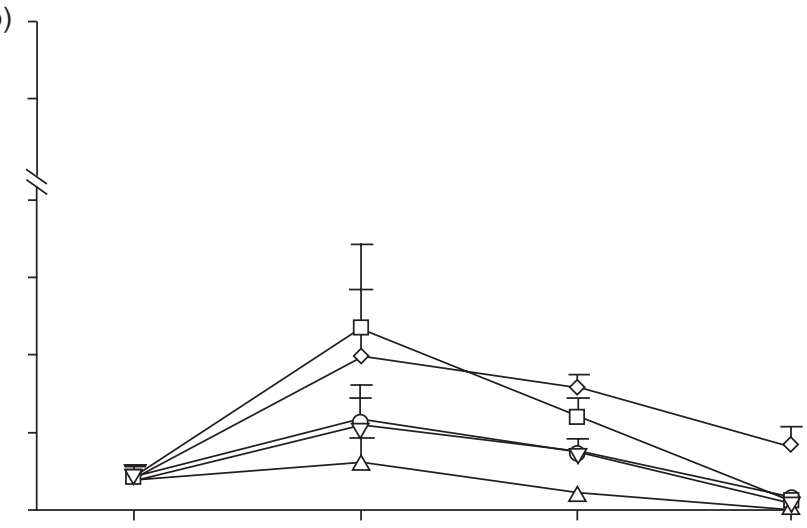

d)

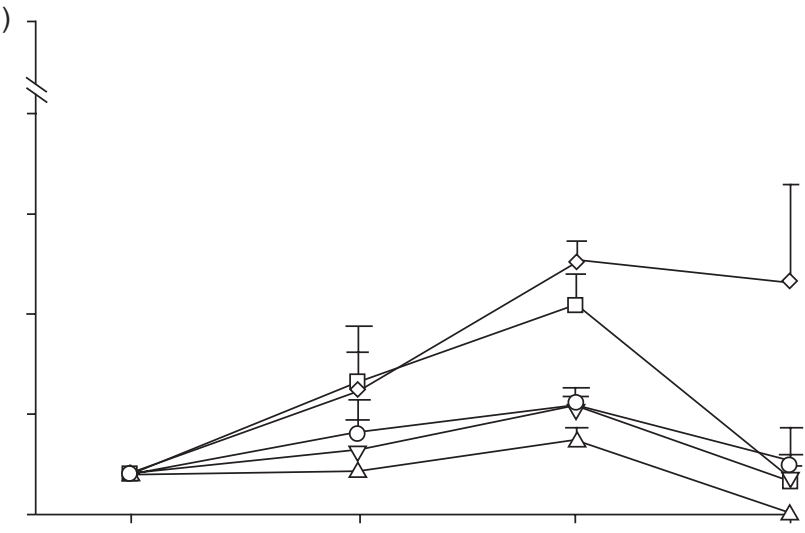

f)

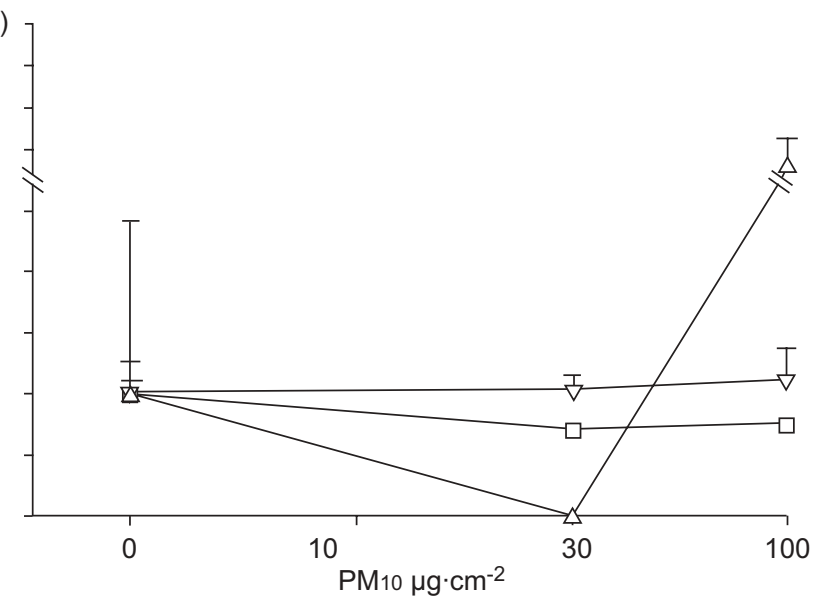

FIGURE 5. Cytokine secretion profile in tricultures, tricultures with endothelial cells, and endothelial cells alone. a and b) Triculture, c and d) triculture + EAHY926 (endothelial cells), and e and f) EAHY926 alone. Cultures were exposed for $24 \mathrm{~h}$ to $0,10,30$ or $100 \mu \mathrm{g} \cdot \mathrm{cm}^{-2}$ of particles with a $50 \%$ cut-off aerodynamic diameter of $10 \mu \mathrm{m}$ (PM10). The cytokine levels are expressed as percentage of control $\left(0 \mu \mathrm{g} \cdot \mathrm{cm}^{-2} \mathrm{PM} 10\right)$. Data are presented as mean $\pm \mathrm{SD} ; \mathrm{n}=3$. $\mathbf{\square}$ : tumour necrosis factor- $\alpha ;-\mathbf{\bullet}$ : interleukin (IL)-

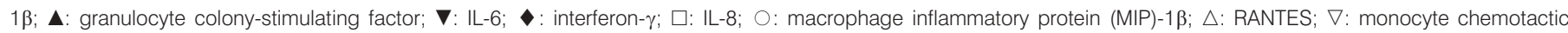
protein-1; $\diamond:$ MIP-1 $\alpha$.

The most significant increases in cytokines were observed in the THP-1 + HMC-1 bicultures and in the tricultures.

\section{Cytokine levels}

Although cytokines can share more than one function, for the sake of simplicity, the mediators measured in the current study were categorised into cytokines (TNF- $\alpha$, IL-6, IL- $1 \beta$, IFN- $\gamma$ and G-CSF) and chemokines (IL-8, MCP-1, MIP-1 $\beta$, MIP- $1 \alpha$ and RANTES) [19].
After PM exposure, large changes were observed in cytokine secretion in the THP-1 + HMC-1 biculture (TNF- $\alpha$ increased $>100$-fold, G-CSF 10-fold and IL-8 increased more than fivefold). In the tricultures and tricultures with endothelial cells, strong responses were observed, although they were not as strong as for the biculture of THP-1 + HMC-1. This difference could be due to: 1) the amount of HMC-1 and THP-1 cells being 3.5-fold smaller in the triculture than in the biculture; and/or 2) the presence of receptors in the A549 cells that could 

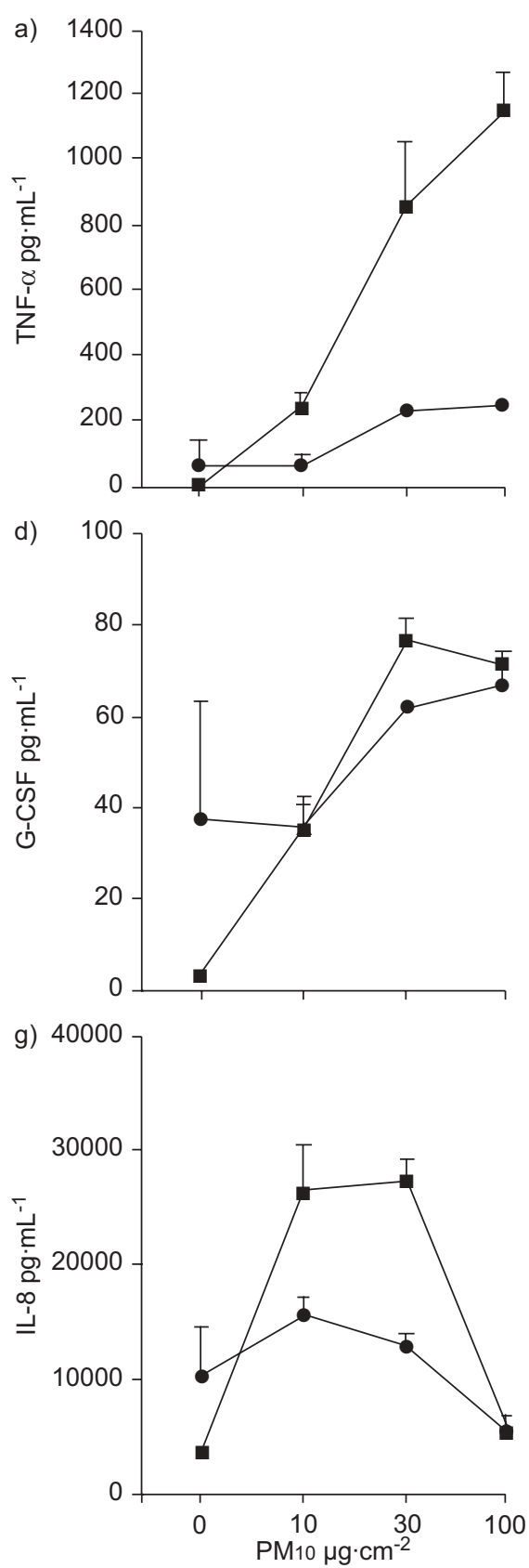

b)

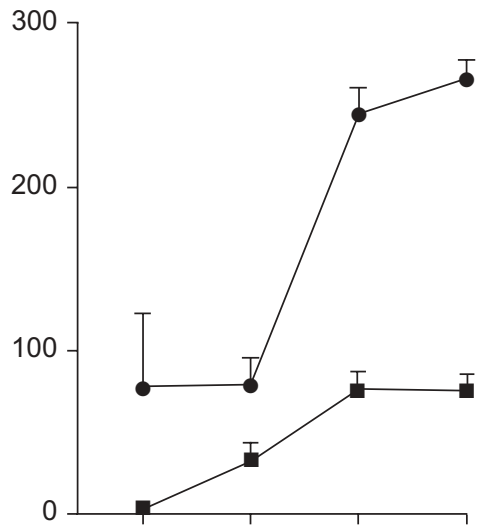

e)

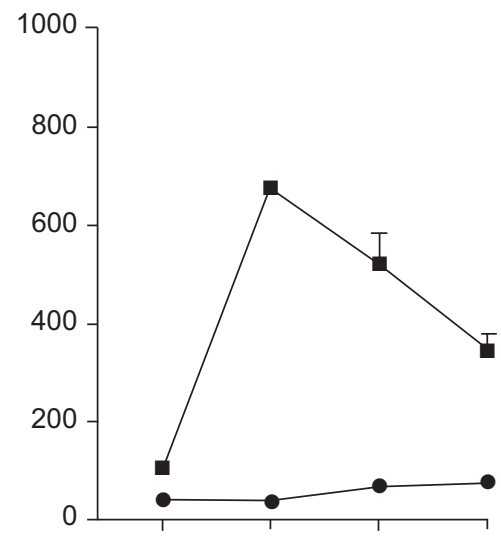

h) 60000

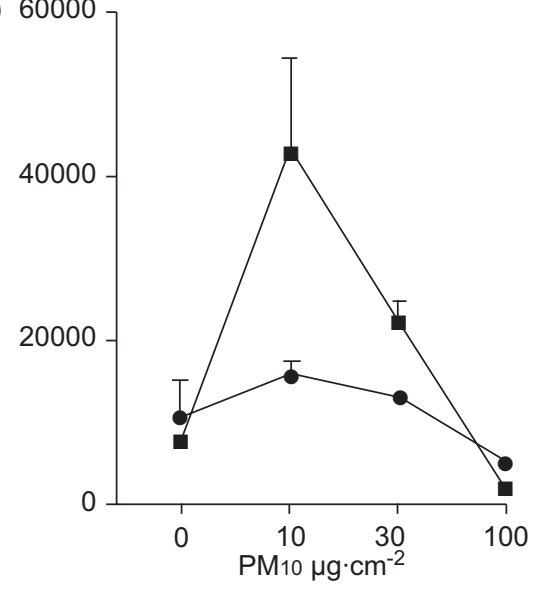

c)

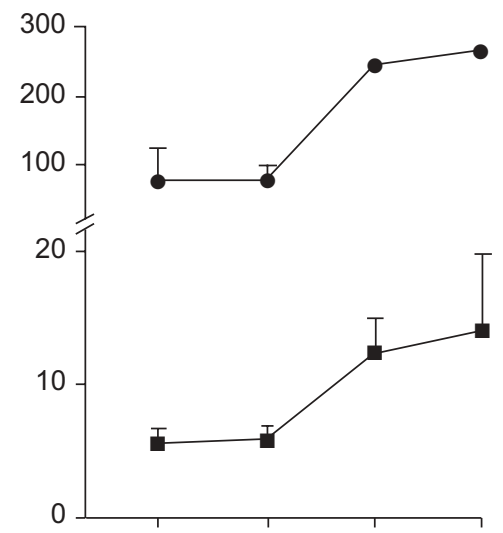

f)

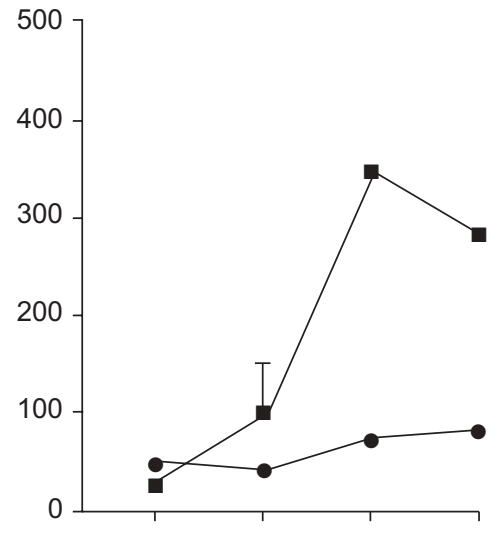

i) 25000

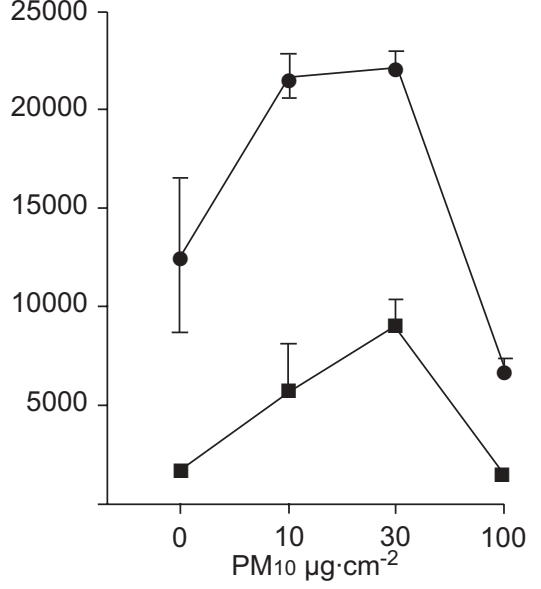

FIGURE 6. Comparison of the observed cytokine concentrations ( $\mathbf{\square})$ with the expected concentrations $(\bullet)$, obtained by adding up the amounts secreted in the single cultures and adjusting for cellular density. a-c) Tumour necrosis factor (TNF)- $\alpha, \mathrm{d}-\mathrm{f}$ ) granulocyte colony-stimulating factor (G-CSF) and g-i) interleukin (IL)-8. a, d and g) THP-1 (macrophage-like cells) + HMC-1 (mast cells) biculture, b, e and h) tricultures and c, $f$ and i) triculture + EAHY926 (endothelial cells). Cultures were exposed for 24 h to $0,10,30$ or $100 \mu \mathrm{g} \cdot \mathrm{cm}^{-2}$ of particles with a $50 \%$ cut-off aerodynamic diameter of $10 \mu \mathrm{m}$ (PM10). Data are presented as mean $\pm \mathrm{SD} ; \mathrm{n}=3$.

trap part of the secreted cytokines. The single cultures and the A549 + HMC-1 bicultures exposed to PM released significantly lower amounts of cytokines.

It is remarkable that PM in the basolateral compartment of endothelial cell cultures induced a large increase in TNF- $\alpha$ and RANTES detectable in the apical compartment but no significant effect on any of the other cytokine mediators. In contrast, when the endothelial cells were introduced above the triculture already exposed for $12 \mathrm{~h}$ to PM, large increases in the levels of most of the cytokines were observed in the apical compartment, but this time without increases in TNF- $\alpha$ or RANTES levels. This indicates that the interactions between different cells change the secretion profiles. This is probably attributable to cross-talk between the different cells, as already shown previously [20], or to the presence of receptors that capture some cytokines, avoiding further detection in culture supernatants [21].

\section{Cellular interaction}

The multiple cell cultures represent an improvement compared with single cell cultures and more closely resemble the 
in vivo situation, yet are still limited to the cells investigated. Macrophages, abundantly present in healthy individuals, in combination with structural cells (epithelial cells), are the main targets of PM. Consequently, this system mimics the very first interaction with PM found in the in vivo situation. The finding that the presence of mast cells increases the production of cytokines fits with the epidemiological findings that air pollution aggravates the presentation of asthma [22]. The histamine secretion by mast cells is considered to be low because, under similar experimental conditions, it has previously been observed that PM only induces the secretion of histamine by HMC-1 cells in the presence of an ionophore [23]. However, it is likely that other mediators, such as enzymes, are released besides histamine.

\section{In vitro observations are consistent with in vivo effects}

Among the pulmonary and systemic effects induced by PM, the increased expression of various cytokines has been described. For instance, TNF- $\alpha$, IL- 6 and IL- 8 are correlated with the pulmonary inflammatory processes after exposure to PM [24, 25]. In relation to the systemic effects: granulocyte-macrophage colony-stimulating factor and G-CSF are related to the mobilisation of cells from the bone marrow [4]; IL-1 $\beta$, IL-6 and TNF- $\alpha$ are related to blood clot formation [26-28]; and TNF- $\alpha$, IL-6 and IL-8 play a role in endothelial dysfunction $[29,30]$. In the system used in the present study, TNF- $\alpha$, G-CSF and IL- 8 are good examples of these cellular mediators.

TNF- $\alpha$ leads to the expression of adhesion molecules involved in recruiting inflammatory cells $[29,30]$. High concentrations of TNF- $\alpha$ were measured in bicultures of THP- $1+$ HMC- 1 exposed to PM when compared with the expected concentrations based on the single culture (fig. 6a). These high concentrations were not observed when epithelial cells were present; on the contrary, significant decreases were found. This reduction of TNF- $\alpha$ in the tricultures and the apical side of the endothelial cells possibly reflects the binding of TNF- $\alpha$ to the abundant A549 cells.

The secretion of G-CSF, a molecule related to the mobilisation of leukocytes from the bone marrow [31], showed a secretion eight times larger for the triculture with EAHY926 cells than for the EAHY926 cells by themselves. In figure $6 \mathrm{~d}-\mathrm{f}$ it is shown that the THP-1 + HMC-1 biculture did not secrete higher concentrations of G-CSF than expected from the single cultures, but the concentrations of G-CSF in the tricultures and tricultures with EAHY926 were significantly larger than expected, especially at the apical side of the triculture with EAHY926. The increases in G-CSF concentrations followed a linear concentration-response pattern. The current authors assume that the concentration of G-CSF observed on the apical side is released by the endothelial cells and not by the translocation of the molecule from the basolateral compartment. This strengthens the hypothesis that the present system mimics the in vivo signal that triggers G-CSF secretion related to systemic effects as a result of PM exposure.

IL-8 is an important pro-inflammatory cytokine related to the recruitment of neutrophils. Controversial results have been published so far, as some studies reported increases in IL-8 secretion after PM exposure $[32,33]$ while others reported decreases in the same cytokine [20, 34]. A study of respiratory damage in children chronically exposed to urban pollution in Mexico City showed that serum levels of IL-8 were decreased when compared with children living in a cleaner environment [35]. The downregulation of IL-8 has been related to different factors, such as relatively late sampling [36], the presence of IL-4 and IL-10 [37], and soluble receptors of TNF- $\alpha$ or CD14 [38, 39]. In the present study, decreases were observed in the IL- 8 secretion by A549 cells and by the biculture of A549 + HMC-1, but large increase in IL-8 secretion were observed in the HMC-1 + THP-1 biculture, the triculture and the triculture with EAHY926 at concentrations of 10 and $30 \mu \mathrm{g} \cdot \mathrm{cm}^{-2} \mathrm{PM} 10$, followed by a decrease at $100 \mu \mathrm{g} \cdot \mathrm{cm}^{-2}$. The controversial results for IL- 8 in previous studies may be associated with dose, time of exposure, type of cell exposed and interactions between different cell types. The possibility of cytokines binding to PM cannot be ruled out, as has been previously demonstrated [40].

In vivo and in vitro studies have shown that PM is capable of inducing an endothelial dysfunction phenotype [29, 41, 42] and pro-thrombotic effects $[8,43]$. The translocation of PM into the bloodstream has been considered as a possible mechanism of these effects [44], and dendritic cells may play a role in the translocation of PM [45]. However, considering that PM translocation is probably a relatively limited phenomenon, the communication with endothelial cells of cells that have primary contact with particles may play a more prominent role in the systemic effects of PM. In the present study, indirect evidence of endothelial cell activation by the triculture system previously exposed to the PM is provided.

The existing evidence in humans demonstrates that endothelial dysfunction and cardiovascular effects are related to PM exposure [46, 47]. In animals, PM exposure has been linked to thrombogenesis, endothelium dysfunction and PM translocation $[10,28,42]$. The system presented in the present study is a model that can be used in addition to animal models, including knockout and knock-in animals, and human studies [43]. Due to its relative simplicity (compared with in vivo), it opens the opportunity of exploring in detail the mechanisms related to the local and systemic effects of PM. One possibility is the use of monoclonal antibodies, anti-cytokines or inhibitors of cytokine receptors to block a signal and, therefore, understand how cytokine secretion and cellular interactions are regulated [48].

\section{Conclusion}

In conclusion, a novel in vitro system was developed, which mimics cell communication within the lung, thus leading to a better understanding of the different cellular mechanisms related to the responses after exposure to particulate matter or any other contaminant, such as endotoxin or transition metals. The bicultures, tricultures and tricultures with endothelial cells provide results that are consistent with the local and systemic effects, such as inflammation, endothelial dysfunction and bone marrow cell mobilisation, which have been described for particulate matter. This novel system opens the possibility of using specific inhibitors for cytokines and transduction signals, leading to a better understanding of the mechanisms related to the effects of environmental pollutants.

\section{ACKNOWLEDGEMENTS}

HMC-1 cells were kindly provided by J.H. Butterfield (Mayo Clinic, Rochester, MN, USA). The authors would like to thank 
A. Nemmar (Sultan Qaboos University, Muscat, Sultanate of Oman) for his valuable comments on the present manuscript.

\section{REFERENCES}

1 Alfaro-Moreno E, Nawrot TS, Nemmar A, Nemery B. Particulate matter in the environment: pulmonary and cardiovascular effects. Curr Opin Pulm Med 2007; 13: 98-106.

2 Schwarze PE, Ovrevik J, Lag M, et al. Particulate matter properties and health effects: consistency of epidemiological and toxicological studies. Hum Exp Toxicol 2006; 25: 559-579.

3 Ishii H, Fujii T, Hogg JC, et al. Contribution of IL-1 $\beta$ and TNF- $\alpha$ to the initiation of the peripheral lung response to atmospheric particulates (PM10). Am J Physiol Lung Cell Mol Physiol 2004; 287: L176-L183.

4 Ishii H, Hayashi S, Hogg JC, et al. Alveolar macrophageepithelial cell interaction following exposure to atmospheric particles induces the release of mediators involved in monocyte mobilization and recruitment. Respir Res 2005; 6: 87.

5 Dormans JA. The ultrastructure of various cell types in the lung of the rat: a survey. Exp Pathol 1983; 24: 15-33.

6 Fox B, Bull TB, Guz A. Mast cells in the human alveolar wall: and electronmicroscopic study. J Clin Pathol 1981; 34: 1333-1342.

7 Nemmar A, Nemery B, Hoet PH, Vermylen J, Hoylaerts MF. Pulmonary inflammation and thrombogenicity caused by diesel particles in hamsters: role of histamine. Am J Respir Crit Care Med 2003; 168: 1366-1372.

8 Nemmar A, Hoylaerts MF, Hoet PH, Nemery B. Possible mechanisms of the cardiovascular effects of inhaled particles: systemic translocation and prothrombotic effects. Toxicol Lett 2004; 149: 243-253.

9 Salvi S, Blomberg A, Rudell B, et al. Acute inflammatory responses in the airways and peripheral blood after shortterm exposure to diesel exhaust in healthy human volunteers. Am J Respir Crit Care Med 1999; 159: 702-709.

10 Nemmar A, Hamoir J, Nemery B, Gustin P. Evaluation of particle translocation across the alveolo-capillary barrier in isolated perfused rabbit lung model. Toxicology 2005; 208: 105-113.

11 Geys J, Nemery B, Moreno EA, Hoet PH. Cytotoxicity of $\mathrm{SiO}_{2}$ in A549 cells. Toxicol Appl Pharmacol 2007; 220: 225.

12 Smith BT. Cell line A549: a model system for the study of alveolar type II cell function. Am Rev Respir Dis 1977; 115: 285-293.

13 Don Porto Carero A, Hoet PH, Verschaeve L, Schoeters G, Nemery B. Genotoxic effects of carbon black particles, diesel exhaust particles, and urban air particulates and their extracts on a human alveolar epithelial cell line (A549) and a human monocytic cell line (THP-1). Environ Mol Mutagen 2001; 37: 155-163.

14 Butterfield JH, Weiler D, Dewald G, Gleich GJ. Establishment of an immature mast cell line from a patient with mast cell leukemia. Leuk Res 1988; 12: 345-355.

15 Suggs JE, Madden MC, Friedman M, Edgell CJ. Prostacyclin expression by a continuous human cell line derived from vascular endothelium. Blood 1986; 68: 825-829.

16 Stone KC, Mercer RR, Gehr P, Stockstill B, Crapo JD. Allometric relationships of cell numbers and size in the mammalian lung. Am J Respir Cell Mol Biol 1992; 6: 235-243.
17 Brown DM, Hutchison L, Donaldson K, Stone V. The effects of PM10 particles and oxidative stress on macrophages and lung epithelial cells: modulating effects of calcium-signaling antagonists. Am J Physiol Lung Cell Mol Physiol 2007; 292: L1444-L1451.

18 Jalava PI, Salonen RO, Pennanen AS, et al. Heterogeneities in inflammatory and cytotoxic responses of RAW 264.7 macrophage cell line to urban air coarse, fine, and ultrafine particles from six European sampling campaigns. Inhal Toxicol 2007; 19: 213-225.

19 Borish LC, Steinke JW. 2. Cytokines and chemokines. J Allergy Clin Immunol 2003; 111: Suppl. 2, S460-S475.

20 Miyajima A, Kitamura T, Harada N, Yokota T, Arai K. Cytokine receptors and signal transduction. Annu Rev Immunol 1992; 10: 295-331.

21 de Jager W, Rijkers GT. Solid-phase and bead-based cytokine immunoassay: a comparison. Methods 2006; 38: 294-303.

22 Holgate ST, Polosa R. The mechanisms, diagnosis, and management of severe asthma in adults. Lancet 2006; 368: 780-793.

23 Alfaro-Moreno E, Hoet P, Nemmar A, et al. Human mast cell activation by urban particulate matter. Am J Respir Crit Care Med 2007; 175: A456.

24 Dybdahl M, Risom L, Bornholdt J, Autrup H, Loft S, Wallin H. Inflammatory and genotoxic effects of diesel particles in vitro and in vivo. Mutat Res 2004; 562: 119-131.

25 Yamamoto S, Tin-Tin-Win-Shwe, Ahmed S, Kobayashi T, Fujimaki H., Effect of ultrafine carbon black particles on lipoteichoic acid-induced early pulmonary inflammation in BALB/c mice. Toxicol Appl Pharmacol 2006; 213: 256-266.

26 Baccarelli A, Zanobetti A, Martinelli I, et al. Effects of exposure to air pollution on blood coagulation. J Thromb Haemost 2007; 5: 252-260.

27 Esmon CT. Does inflammation contribute to thrombotic events? Haemostasis 2000; 30: Suppl. 2, 34-40.

28 Nemmar A, Hoylaerts MF, Hoet PH, et al. Ultrafine particles affect experimental thrombosis in an in vivo hamster model. Am J Respir Crit Care Med 2002; 166: 998-1004.

29 Alfaro-Moreno E, López-Marure R, Montiel-Dávalos A, et al. E-Selectin expression in human endothelial cells exposed to PM10: the role of endotoxin and insoluble fraction. Environ Res 2007; 103: 221-228.

30 Nemmar A, Hoet PH, Vandervoort P, Dinsdale D, Nemery B, Hoylaerts MF. Enhanced peripheral thrombogenicity after lung inflammation is mediated by platelet-leukocyte activation: role of P-selectin. J Thromb Haemost 2007; 5: 1217-1226.

31 Mukae H, Vincent R, Quinlan K, et al. The effect of repeated exposure to particulate air pollution (PM10) on the bone marrow. Am J Respir Crit Care Med 2001; 163: 201-209.

32 Becker S, Mundandhara S, Devlin RB, Madden M. Regulation of cytokine production in human alveolar macrophages and airway epithelial cells in response to ambient air pollution particles: further mechanistic studies. Toxicol Appl Pharmacol 2005; 207: Suppl. 2, 269-275.

33 Hetland RB, Cassee FR, Refsnes M, et al. Release of inflammatory cytokines, cell toxicity and apoptosis in epithelial lung cells after exposure to ambient air particles of different size fractions. Toxicol In Vitro 2004; 18: 203-212.

34 Veranth JM, Moss TA, Chow JC, et al. Correlation of in vitro cytokine responses with the chemical composition 
of soil-derived particulate matter. Environ Health Perspect 2006; 114: 341-349.

35 Calderón-Garcidueñas L, Mora-Tiscareño A, Fordham LA, et al. Respiratory damage in children exposed to urban pollution. Pediatr Pulmonol 2003; 36: 148-161.

36 Tian B, Nowak DE, Brasier AR. A TNF-induced gene expression program under oscillatory NF- $\kappa \mathrm{B}$ control. $B M C$ Genomics 2005; 6: 137.

37 Ameixa C, Friedland JS. Down-regulation of interleukin-8 secretion from Mycobacterium tuberculosis-infected monocytes by interleukin- 4 and -10 but not by interleukin-13. Infect Immun 2001; 69: 2470-2476.

38 Hattar K, Fink L, Fietzner K, et al. Cell density regulates neutrophil IL-8 synthesis: role of IL-1 receptor antagonist and soluble TNF receptors. J Immunol 2001; 166: 6287-6293.

39 Sohn EJ, Paape MJ, Bannerman DD, Connor EE, Fetterer RH, Peters RR. Shedding of sCD14 by bovine neutrophils following activation with bacterial lipopolysaccharide results in down-regulation of IL-8. Vet Res 2007; 38: 95-108.

40 Kocbach A, Totlandsdal AI, Lag M, Refsnes M, Schwarze PE. Differential binding of cytokines to environmentally relevant particles: a possible source for misinterpretation of in vitro results? Toxicol Lett 2008; 176: 131-137.

41 Montiel-Dávalos A, Alfaro-Moreno E, López-Marure R. PM2.5 and PM10 induce the expression of adhesion molecules and the adhesion of monocytic cells to human umbilical vein endothelial cells. Inhal Toxicol 2007; 19: Suppl. 1, 91-98.

42 Nurkiewicz TR, Porter DW, Barger M, et al. Systemic microvascular dysfunction and inflammation after pulmonary particulate matter exposure. Environ Health Perspect 2006; 114: 412-419.

43 Mutlu GM, Green D, Bellmeyer A, et al. Ambient particulate matter accelerates coagulation via an IL-6dependent pathway. J Clin Invest 2007; 117: 2952-2961.

44 Nemmar A, Hoet PH, Vanquickenborne B, et al. Passage of inhaled particles into the blood circulation in humans. Circulation 2002; 105: 411-414.

45 Blank F, Rothen-Rutishauser B, Gehr P. Dendritic cells and macrophages form a transepithelial network against foreign particulate antigens. Am J Respir Cell Mol Biol 2007; 36: 669-677.

46 Mills NL, Törnqvist H, Robinson SD, et al. Diesel exhaust inhalation causes vascular dysfunction and impaired endogenous fibrinolysis. Circulation 2005; 112: 3930-3936.

47 Törnqvist H, Mills NL, Gonzalez M, et al. Persistent endothelial dysfunction in humans after diesel exhaust inhalation. Am J Respir Crit Care Med 2007; 176: 395-400.

48 Herseth J, Refsnes M, Lag M, Hetland G, Schwarze P. IL-1 $\beta$ as a determinant in silica-induced cytokine responses in monocyte-endothelial cell co-cultures. Hum Exp Toxicol 2008; 27: 387-399. 